\title{
Children immunization - knowledge and attitudes of parents
}

Wiedza i postawy rodziców wobec szczepień ochronnych u dzieci

\author{
Alina Trojanowska, Danuta Zarzycka, Magdalena Brodowicz-Król, \\ Arkadiusz Jędrzejewski, Anna Wiktor
}

Katedra i Zakład Pielęgniarstwa Pediatrycznego Wydziału Nauk o Zdrowiu Uniwersytetu Medycznego w Lublinie/ Chair and Department of Paediatric Nursing, Faculty of Health Sciences, Medical University of Lublin

\author{
CORRESPONDING AUTHOR/AUTOR DO KORESPONDENCJI: \\ Alina Trojanowska \\ Chair and Department of Paediatric Nursing/Katedra i Zakład Pielęgniarstwa Pediatrycznego \\ Medical University of Lublin/Uniwersytet Medyczny w Lublinie \\ ul. Gębali 6, 20-093 Lublin \\ e-mail: zakladpp@umlub.pl \\ tel. 817185375
}

ABSTRACT

Key words:

STRESZCZENIE

Słowa kluczowe:
CHILDREN IMMUNIZAIION - KNOWLEDEE AND ATTITUDES OF PARENIS

Aim. The aim of the study was to investigate parents' knowledge and attitudes towards compulsory immunization of their children. Material and methods. The research was conducted with the survey questionnaire among 110 randomly chosen parents aged 18-40 whose infants were inpatients at the University Children's Hospital in Lublin.

Results. The study revealed that parents were poorly informed about the age of the first vaccination of their infant, compulsory and recommended vaccines, combined vaccines, contraindications for vaccination and adverse reactions following immunization. More than $50 \%$ of the parents had a rather positive attitude towards vaccination. However, one fifth admitted that they had seen campaigns which presented immunization of children as harmful. The most popular opinion among the respondents was that compulsory and recommended vaccinations for children should be given only against the most dangerous diseases. The majority of parents considered vaccinations to be safe and only a small percentage of parents were against immunizing their children due to possible health complications. Most of the parents were willing to immunize their children with all the compulsory vaccines and only several recommended ones (as they are not free of charge). Many of them declared they would choose combined vaccines.

Conclusions. Attitudes of parents towards immunization of children varied in the studied group. We concluded that parents were generally poorly informed about immunization of infants. The fact that knowledge about vaccinations may influence parents' future decisions to protect their children against numerous infectious diseases calls for intensified education on the subject.

immunization, children, parents, knowledge, attitudes

\section{WIEDZA I POSTAWY RODZICOW WOBEC SZCZEPIEN OCHRONNYCH U DZLIEC}

Cel pracy. Celem badań była próba poznania stanu wiedzy oraz postaw rodziców wobec obowiązku realizacji szczepień ochronnych u własnych dzieci.

Materiał i metodyka. Badania metodą sondażu diagnostycznego przy użyciu techniki ankiety przeprowadzono wśród 110 losowo wybranych rodziców w wieku 18-40 lat, których niemowlęta były hospitalizowane w Uniwersyteckim Szpitalu Dziecięcym w Lublinie. Wyniki badań. Ujawniono braki wiedzy rodziców odnośnie: wieku I szczepienia niemowlęcia, szczepień obowiązkowych i zalecanych, szczepionek skojarzonych oraz przeciwwskazań do szczepień, jak i niepożądanych odczynów poszczepiennych. Ponad połowa rodziców była nastawiona do szczepień raczej pozytywnie, natomiast 1/5 z nich przyznała, że miała kontakt z akcjami ukazującymi szkodliwość szczepień ochronnych u dzieci. Ankietowani najczęściej wyrażali opinię, że szczepienia obowiązkowe i zalecane u dzieci powinny dotyczyć tylko najgroźniejszych chorób. Większość badanych uważała, że szczepienia są bezpieczne i tylko znikomy odsetek jest przeciwny szczepieniu swoich dzieci z powodu mogących wystąpić powikłań. Rodzice najczęściej byli też zmotywowani do szczepienia swoich dzieci wszystkimi szczepionkami obowiązkowymi i tylko niektórymi zalecanymi, bo były płatne, a wielu z nich deklarowało, że wybierze szczepionkę skojarzoną.

Wnioski. Postawy rodziców wobec szczepień ochronnych u dzieci w badanej grupie były zróżnicowane. Stwierdzony dość niski poziom wiedzy na temat szczepień ochronnych wśród rodziców niemowląt, mogący w przyszłości chronić ich dzieci przed wystąpieniem wielu chorób zakaźnych, wskazuje na konieczność intensyfikacji wśród nich działań edukacyjnych w tym zakresie.

szczepienia ochronne, dzieci, rodzice, wiedza, postawy 


\section{INTRODUCTION}

It is estimated that approximately 4 million infants, including 2.2 million aged $<6$ months, die every year due to infectious diseases [1,2]. Many of these infections could be prevented with vaccines, which are becoming increasingly safe and effective. Current recommendations for immunization of infants have been formulated on the basis of the extensive research $[1,2,3,4,5,6]$. Herd immunity developed as a result of preventive vaccinations is reversible, i.e. neglecting immunization may cause an increase in the incidence of infectious diseases, which can be prevented if the entire population is immunized. The number of non-immunized children in Poland has been systematically growing as parents frequently refuse to have their children vaccinated $[1,2]$. The phenomenon has been extensively studied due to the seriousness of the problem. WHO has appointed a group of experts on vaccination, whose task is to analyse factors influencing negative attitudes towards immunization among parents and to find means to counteract the trend. Unfortunately, recent years have shown the increasing popularity of anti-vaccination movements, which frequently misinform parents about vaccination and encourage them to stop inoculating their children. They also promote acquiring immunity by infecting a child intentionally, for example during "chicken pox parties", which in some cases may lead to the child's death as a result of disease complications $[2,7,8,9,10,11]$. This is why parents should be constantly educated and informed about the importance of vaccination for prevention of infectious diseases.

\section{AIM}

The aim of the study was to investigate parents' knowledge and attitudes towards compulsory immunization of their children.

\section{MATERIALS AND METHODS}

A diagnostic survey was conducted on 110 randomly

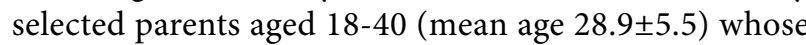
infants were inpatients at the Department of Infant Pathology and Cardiology, University Children's Hospital in Lublin. We used survey questionnaire created for the purpose of this study. It consisted of 35 questions assessing the knowledge of parents and their attitudes towards immunization of children. The questions assessing knowledge were scored as follows: 1 point for a correct answer and 0 points for an incorrect answer. Parents' knowledge about vaccination was assessed according to the following criteria: a score of less than $51 \%$ pts - poorly informed, $51-75 \%$ pts - partially informed, more than $75 \%$ pts well-informed. The data obtained was statistically analysed in the Statistica 9.1 software. A $\chi^{2}$ test was used to determine the significance of differences between the studied features. The significance threshold was set at $\mathrm{p}<0.05$.

\section{RESULTS}

The vast majority of the surveyed parents were women $(89.1 \%)$. The majority of respondents $(67.3 \%)$ lived in Vol.15, №. 4(57), 2016

a city or town, while only $32.7 \%$ lived in the countryside. The level of education within the group varied as well. Parents with higher education constituted $46.4 \%$ of the surveyed group; $36.4 \%$ had secondary school education, $15.4 \%$ - vocational education and $1.8 \%$ - primary education. More than half of the parents (58.18\%) worked, the remaining were unemployed. Nearly all of the respondents (98.2\%) were part of nuclear families with one (49.1\%) or two $(37.3 \%)$ children. The respondents subjectively assessed their financial situation as good $(60.1 \%)$ or average $(25.5 \%)$.

The analysis of the results according to the adopted criteria showed that more than half (58.2\%) of the parents were poorly informed about preventive vaccination of children, one third (36.36\%) were partially informed and only $5.46 \%$ were well-informed. The study revealed a lack of knowledge in the parents regarding the age of the first vaccination of infants $(40.9 \%)$, compulsory $(2.7 \%)$ and recommended (11.8\%) vaccines, combined vaccines, contraindications for vaccination $(40.9 \%)$ and adverse reactions following immunization $(38.2 \%)$. Personal conversation with a doctor $(92.7 \%)$ or a nurse $(68.2 \%)$ was the most reliable source of information on vaccinations for the majority of the surveyed.

Half of the respondents (50.9\%) had a rather positive attitude towards vaccinations (particularly men: $p=0.02$ ), however one fifth of the parents (22 people) admitted that they had seen campaigns, mostly on the Internet, which presented immunization of children as harmful (Fig. 1, Tab. 1).

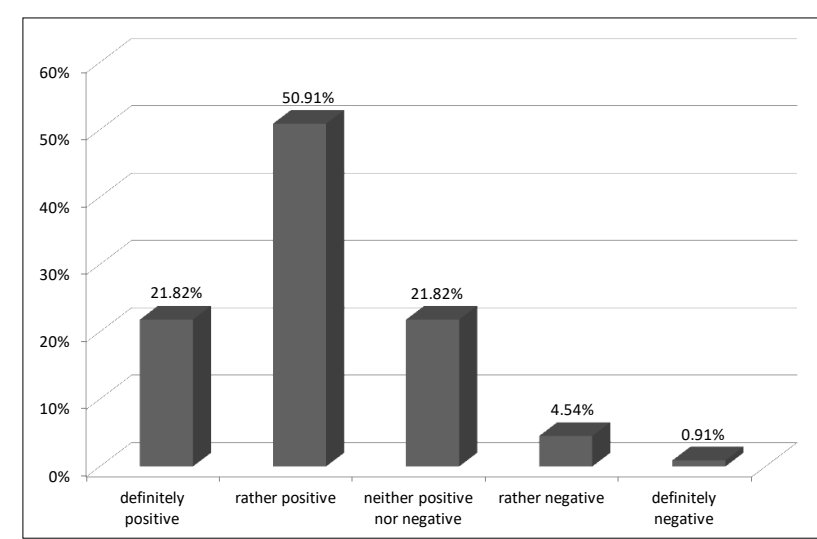

Fig 1. General attitudes of parents towards immunization of children.

Tab. 1. Sources of information for parents on the adverse effects of immunization of children by rank.

\begin{tabular}{|l|c|c|c|c|c|}
\hline $\begin{array}{l}\text { Location/person/ } \\
\text { source of nformation }\end{array}$ & $\begin{array}{c}\text { Number } \\
\text { (n) }\end{array}$ & Mean & Minimum & Maximum & Rank \\
\hline Internet & 22 & 2.59 & 1.00 & 5.00 & 1 \\
\hline $\begin{array}{l}\text { other children's parents } \\
\text { (media) }\end{array}$ & 22 & 3.05 & 1.00 & 5.00 & 2 \\
\hline $\begin{array}{l}\text { TV, radio (experts, } \\
\text { journalists) }\end{array}$ & 22 & 3.09 & 1.00 & 5.00 & 3 \\
\hline \begin{tabular}{l} 
press (experts, journalists) \\
\hline $\begin{array}{l}\text { nurse/midwife } \\
\text { (surgery, conversation) }\end{array}$
\end{tabular} & 22 & 3.77 & 1.00 & 5.00 & 4 \\
\hline $\begin{array}{l}\text { general practitioner/ } \\
\text { paediatrician } \\
\text { (surgery, conversation) }\end{array}$ & 22 & 4.27 & 2.00 & 5.00 & 6 \\
\hline $\begin{array}{l}\text { family/friends } \\
\text { (home, conversation) }\end{array}$ & 22 & 4.41 & 1.00 & 5.00 & 7 \\
\hline information leaflets & 22 & 4.50 & 1.00 & 5.00 & 8 \\
\hline
\end{tabular}


The most popular opinion among the respondents was that children should be immunized only against the most dangerous diseases with compulsory (45.5\%) and recommended (65.5\%) vaccines (Tab. 2)

Tab. 2. Parents' opinion on compulsory and recommended vaccination of children.

\begin{tabular}{|l|c|c|}
\hline \multicolumn{1}{|c|}{ COMPULSORY VACCINATIONS } & $\begin{array}{c}\text { Number } \\
\text { (n) }\end{array}$ & $\begin{array}{c}\text { Percentage } \\
\text { (\%) }\end{array}$ \\
\hline $\begin{array}{l}\text { There should be as many vaccines as possible so } \\
\text { that the child is protected against the highest } \\
\text { possible number of diseases. }\end{array}$ & 47 & 42.73 \\
\hline $\begin{array}{l}\text { Children should be immunized only against the } \\
\text { most dangerous diseases. Parents should decide } \\
\text { whether their child is to have other vaccinations. }\end{array}$ & 50 & 45.46 \\
\hline $\begin{array}{l}\text { There should be no compulsory vaccination. } \\
\text { All decisions concerning vaccination should be } \\
\text { made by parents. }\end{array}$ & 6 & 5.45 \\
\hline I don't know/it is difficult to say. & 7 & 6.36 \\
\hline Total & 110 & 100.00 \\
\hline $\begin{array}{l}\text { There should be as many additional vaccinations } \\
\text { as possible to protect the child against all possible } \\
\text { diseases. }\end{array}$ & 15 & 13.64 \\
\hline $\begin{array}{l}\text { There should be some additional vaccinations } \\
\text { to protect the child against the most dangerous } \\
\text { diseases. }\end{array}$ & 72 & $\mathbf{\text { Number }}$ \\
\hline $\begin{array}{l}\text { There is no need for additional vaccinations. } \\
\text { Compulsory vaccinations provide sufficient } \\
\text { protection. }\end{array}$ & 11 & 10.05 .45 \\
\hline $\begin{array}{l}\text { Children should not be vaccinated at all, neither } \\
\text { with compulsory nor additional vaccines. }\end{array}$ & 1 & 0.91 \\
\hline I don't know/it is difficult to say. & 11 & 10.00 \\
\hline Total & & 100.00 \\
\hline
\end{tabular}

Tab. 3. Parents' declarations regarding the choice of vaccines for their children.

\begin{tabular}{|l|c|c|}
\hline \multicolumn{1}{|c|}{ TYPE OF VACCINATIONS } & $\begin{array}{c}\text { Number } \\
\text { (n) }\end{array}$ & $\begin{array}{c}\text { Percentage } \\
\text { (\%) }\end{array}$ \\
\hline only compulsory because they are free & 20 & 18.18 \\
\hline only compulsory because they are sufficient & 21 & 19.09 \\
\hline $\begin{array}{l}\text { all compulsory vaccines but only some of the } \\
\text { recommended ones because they are not free }\end{array}$ & 33 & 30.00 \\
\hline $\begin{array}{l}\text { all compulsory vaccines and only some of the } \\
\text { recommended ones (against the most dangerous } \\
\text { diseases) because otherwise there will be too many }\end{array}$ & 18 & 16.36 \\
\hline all compulsory and all recommended ones & 15 & 13.64 \\
\hline $\begin{array}{l}\text { selected compulsory vaccines against the most } \\
\text { dangerous diseases }\end{array}$ & 2 & 1.82 \\
\hline only recommended vaccines & 0 & 0.00 \\
\hline $\begin{array}{l}\text { selected recommended vaccines against the most } \\
\text { dangerous diseases }\end{array}$ & 0 & 0.00 \\
\hline $\begin{array}{l}\text { none because I do not/l am not going to have my } \\
\text { child vaccinated }\end{array}$ & 1 & 0.91 \\
\hline Total & 110 & 100.00 \\
\hline
\end{tabular}

A significant percentage of parents $(60.6 \%)$ considered vaccinations to be safe and only a small percentage $(0.91 \%)$ of parents were against immunizing their children due to possible health complications. Difficulties with immunizing children most often stemmed from high costs of recommended vaccines (56.4\%) and lack of solid knowledge about vaccination (28.2\%). Most of the parents decided to immunize their children with all compulsory vaccines and only several recommended ones as they are not free of charge $(30.0 \%)$. Choosing combined vaccines was declared by $70.0 \%$ of the parents (Tab. 3 ).

\section{DISCUSSION}

Immunization is considered to be one of the most effective methods of eradicating infectious diseases. Epidemiological data shows that childhood infectious diseases are still a major but frequently overlooked health problem $[12,13,14,15]$. This may stem from the fact that the majority of typical infectious diseases have been partially or totally eradicated and they no longer present a serious threat. Many severe diseases and risks associated with them may be prevented by vaccinating a child at an appropriately early age.

On the other hand, the fact that children are vaccinated on a massive scale and some of the vaccines are compulsory arouses opposition among some parents. In recent years, we have witnessed increased activity of anti-vaccination movements which not only question the rationale for expanding the programme of immunization but also oppose the current vaccination schedule. An increasing amount of information on the harmful effects of vaccines on children is being spread with little scientific evidence to support it $[1,2,6,7,8,9,10,11]$. Authors of such publications are concerned that children may be given too many vaccines too early in life and that vaccination may be dangerous to health. One should not forget, however, that due to vaccination, many dangerous infectious diseases were eliminated.

Parents are advised to begin and continue preventive immunization of their children at the time specified in the current vaccination schedule $[1,4,5,6,7,8,12,13,16,17]$. Building awareness of the importance of immunization among parents is crucial for future prevention of infectious diseases in children. The present study has demonstrated that only a small percentage of parents have sufficient (high) knowledge of the subject. One possible reason for this is that they were not provided with relevant information by health care professionals. Similar observations have been made by other authors (e.g. Tarczoń et al., Kuchar et al., Kochman et al.) $[1,2,3,6,11]$. Research on parents' attitudes towards immunization in Poland (e.g. Tymińska et al., Tarczoń et al., Kochman et al.) has shown that vaccines are generally accepted as means of fighting with infectious diseases, what was confirmed in our study $[1,6,11]$.

\section{CONCLUSIONS}

1. Attitudes of parents towards immunization of children varied in the studied group.

2. Parents do not have sufficient knowledge that would allow for effective immunoprophylaxis of their children and should therefore be educated on the subject.

3. The fact that personal conversation with a doctor or a nurse was regarded as the most reliable source and form of information on preventive vaccination should be appropriately used in health education. 


\section{Wiedza i postawy rodziców wobec szczepień ochronnych u dzieci}

\section{WPROWADZENIE}

Dane szacunkowe wskazują, że rocznie $\mathrm{z}$ powodu chorób infekcyjnych umiera na świecie $4 \mathrm{mln}$ niemowląt, w tym ok. 2,2 mln to dzieci do 6. m.ż. [1,2]. Wielu z tych zakażeń można coraz skuteczniej i bezpieczniej zapobiegać stosując szczepienia ochronne. Aktualne rekomendacje dotyczące realizacji szczepień ochronnych u dzieci sformułowano w oparciu o wyniki wielu badań $[1,2,3,4,5,6]$. Odporność zbiorowiskowa uzyskana dzięki szczepieniom ochronnym jest zjawiskiem odwracalnym, tzn. zaniechanie szczepień może spowodować wzrost zapadalności na choroby zakaźne, którym można zapobiec poprzez szczepienia w całej populacji. W Polsce liczba osób nieszczepiących dzieci systematycznie rośnie $[1,2]$. Odmowa poddawania dzieci szczepieniom ochronnym stała się zjawiskiem częstym, a zarazem na tyle poważnym, że poświęca się mu liczne opracowania naukowe $[1,2]$. WHO powołało grupę ekspertów do spraw szczepień ochronnych, której zadaniem jest analiza czynników wpływających na negatywną postawę rodziców wobec szczepień i znalezienie metod zaradczych. Niestety w ostatnich latach coraz bardziej popularne stają się ruchy antyszczepionkowe, które niejednokrotnie rozpowszechniają błędne informacje na temat szczepień oraz nakłaniają rodziców do zaprzestania szczepień ich dzieci, czy też preferują uzyskanie odporności poprzez celowe zakażenie dziecka, np. drogą „ospa party”, co może się skończyć nawet śmiercią dziecka w wyniku powikłań choroby $[2,7,8,9,10,11]$. Dlatego tak ważne staje się ciągłe podnoszenie wiedzy i świadomości rodziców odnośnie znaczenia szczepień w profilaktyce chorób zakaźnych.

\section{CEL PRACY}

Celem badań była próba poznania stanu wiedzy oraz postaw rodziców wobec obowiązku realizacji szczepień ochronnych u własnych dzieci.

\section{MATERIAŁ I METODYKA}

Badania metodą sondażu diagnostycznego przeprowadzono wśród 110 losowo wybranych rodziców w wieku

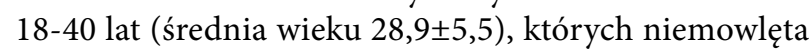
były hospitalizowane w Klinice Patologii Niemowląt i Klinice Kardiologii Dziecięcej Uniwersyteckiego Szpitala Dziecięcego w Lublinie. Jako narzędzie badawcze wykorzystano kwestionariusz ankiety stworzony na potrzeby pracy, który składał się z 35 pytań oceniających wiedzę rodziców oraz ich postawy wobec szczepień ochronnych u dzieci. Pytania oceniające wiedzę były punktowane następująco: 1 pkt za odpowiedź prawidłową i 0 pkt za odpowiedź błędną. Przyjęto trzy kryteria oceny wiedzy rodziców na temat szczepień: do 51\% pkt: wiedza niska, 51-75\% pkt: przeciętna, powyżej 75\% pkt: wysoka.
Zebrany materiał poddano analizie statystycznej z zastosowaniem programu Statistica 9.1. Istotność różnic między badanymi cechami sprawdzono testem $\chi^{2}$. Przyjęto poziom istotności statystycznej $\mathrm{p}<0,05$.

\section{WYNIKI BADAŃ}

Wśród badanych rodziców zdecydowaną większość stanowiły kobiety $(89,1 \%)$. Większość ankietowanych $(67,3 \%)$ zamieszkiwała w mieście, a tylko $32,7 \%$ na wsi. Pod względem wykształcenia grupa ta także była zróżnicowana. Wykształceniem wyższym legitymowało się $46,4 \%$ rodziców, średnim 36,4\%, zawodowym 15,4\%, a podstawowym $1,8 \%$. Ponad połowa rodziców $(58,18 \%)$ była aktywna zawodowo, pozostali to osoby nie pracujące. Prawie wszyscy badani $(98,2 \%)$ mieli pełne rodziny, z jednym $(49,1 \%)$ lub dwojgiem $(37,3 \%)$ dzieci. Sytuacja materialna badanych w ich subiektywnej ocenie w większości była dobra $(60,1 \%)$ lub przeciętna $(25,5 \%)$.

Analiza materiału badawczego według przyjętych kryteriów oceny wykazała, że poziom wiedzy rodziców na temat szczepień ochronnych u dzieci u ponad połowy $\mathrm{z}$ nich $(58,2 \%)$ jest niski, co trzeci rodzic ma przeciętna wiedzę $(36,36 \%)$ i jedynie niewielki odsetek $(5,46 \%)$ wysoką. Ujawniono braki wiedzy, m.in. odnośnie: wieku I szczepienia niemowlęcia $(40,9 \%)$, szczepień obowiązkowych $(2,7 \%)$ i zalecanych $(11,8 \%)$, szczepionek skojarzonych oraz przeciwwskazań do szczepień $(45,5 \%)$ i niepożądanych odczynów poszczepiennych $(38,2 \%)$. Dla większości ankietowanych najbardziej wiarygodną formą przekazu informacji o szczepieniach były indywidualne rozmowy z lekarzem $(92,7 \%)$ i pielęgniarką $(68,2 \%)$.

Spośród badanych połowa $(50,9 \%)$ była nastawiona do szczepień raczej pozytywnie (zwłaszcza mężczyźni: $\mathrm{p}=0,02$ ), natomiast $1 / 5 \mathrm{z}$ nich (22 osoby) przyznała, że miała kontakt $\mathrm{z}$ akcjami przedstawiającymi szkodliwość szczepień ochronnych u dzieci, szczególnie poprzez Internet (ryc. 1, tab. 1).

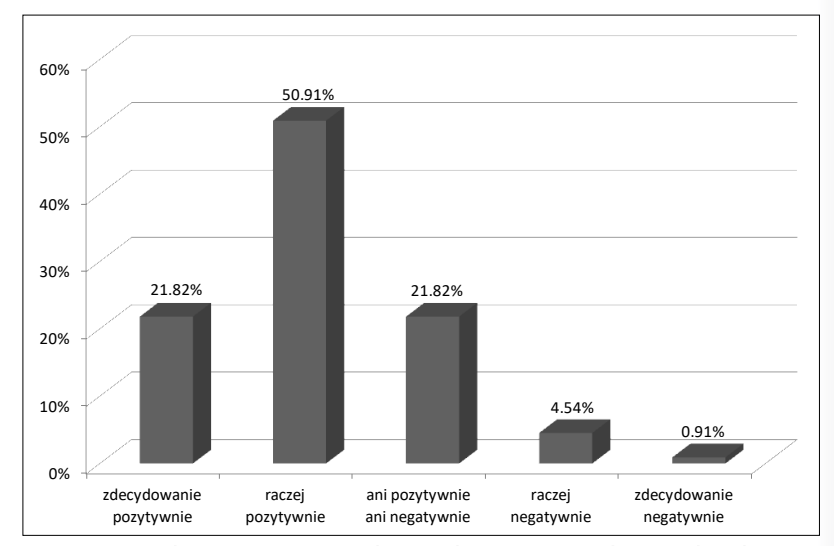

Rys 1. Ogólne nastawienie rodziców do szczepień ochronnych u dzieci. 
Tab. 1. Źródła informacji rodziców na temat niekorzystnych skutków szczepień ochronnych u dzieci wg rang.

\begin{tabular}{|l|c|c|c|c|c|}
\hline \multicolumn{1}{|c|}{$\begin{array}{c}\text { Miejsce/osoba/ } \\
\text { sposób }\end{array}$} & $\begin{array}{c}\text { Liczba } \\
\text { (n) }\end{array}$ & Średnia & Minimum & Maksimum & Ranga \\
\hline Internet & 22 & 2,59 & 1,00 & 5,00 & 1 \\
\hline $\begin{array}{l}\text { rodzice innych dzieci } \\
\text { (media) }\end{array}$ & 22 & 3,05 & 1,00 & 5,00 & 2 \\
\hline $\begin{array}{l}\text { TV, radio (eksperci, } \\
\text { dziennikarze) }\end{array}$ & 22 & 3,09 & 1,00 & 5,00 & 3 \\
\hline $\begin{array}{l}\text { prasa (eksperci, } \\
\text { dziennikarze) }\end{array}$ & 22 & 3,77 & 1,00 & 5,00 & 4 \\
\hline $\begin{array}{l}\text { pielęgniarka/położna } \\
\text { (gabinet, rozmowa) }\end{array}$ & 22 & 4,18 & 1,00 & 5,00 & 5 \\
\hline $\begin{array}{l}\text { lekarz rodzinny/ } \\
\text { pediatra (gabinet, } \\
\text { rozmowa) }\end{array}$ & 22 & 4,27 & 2,00 & 5,00 & 6 \\
\hline $\begin{array}{l}\text { rodzina/znajomi } \\
\text { (dom, rozmowa) }\end{array}$ & 22 & 4,41 & 1,00 & 5,00 & 7 \\
\hline ulotki informacyjne & 22 & 4,50 & 1,00 & 5,00 & 8 \\
\hline
\end{tabular}

Ankietowani najczęściej wyrażali opinię, że szczepienia obowiązkowe $(45,5 \%)$ i zalecane $(65,5 \%)$ powinny dotryczyć tylko najgroźniejszych chorób (tab.2).

Tab. 2. Opinia rodziców na temat szczepień obowiązkowych i zalecanych u dzieci.

\begin{tabular}{|c|c|c|}
\hline SZCZEPIENIA OBOWIĄZKOWE & $\begin{array}{l}\text { Liczba } \\
\text { (n) }\end{array}$ & $\begin{array}{c}\text { Procent } \\
(\%)\end{array}$ \\
\hline $\begin{array}{l}\text { Powinny obejmować jak najwięcej szczepień, aby } \\
\text { chronić dziecko przed możliwie największą liczbą } \\
\text { chorób. }\end{array}$ & 47 & 42,73 \\
\hline $\begin{array}{l}\text { Powinny dotyczyć tylko najgroźniejszych chorób. } \\
\text { Pozostałe szczepienia powinny zależeć od decyzji } \\
\text { rodziców. }\end{array}$ & 50 & 45,46 \\
\hline $\begin{array}{l}\text { Nie powinno być żadnych szczepień } \\
\text { obowiązkowych. Wszystkie decyzje dotyczące } \\
\text { szczepień powinny być podejmowane przez } \\
\text { rodziców dzieci. }\end{array}$ & 6 & 5,45 \\
\hline Nie wiem/trudno powiedzieć. & 7 & 6,36 \\
\hline Razem & 110 & 100,00 \\
\hline SZCZEPIENIA ZALECANE & $\begin{array}{l}\text { Liczba } \\
\text { (n) }\end{array}$ & $\begin{array}{c}\text { Procent } \\
(\%)\end{array}$ \\
\hline $\begin{array}{l}\text { Warto stosować jak najwięcej szzzepień } \\
\text { dodatkowych, aby zabezpieczyć się przeciwko } \\
\text { wszystkim możliwym chorobom. }\end{array}$ & 15 & 13,64 \\
\hline $\begin{array}{l}\text { Warto zastosować niektóre szzzepienia dodatkowe, } \\
\text { aby zabezpieczyć się przeciwko najgroźniejszym } \\
\text { chorobom. }\end{array}$ & 72 & 65,45 \\
\hline $\begin{array}{l}\text { Nie warto stosować szczepień dodatkowych. } \\
\text { Szczepienia obowiązkowe są wystarczającą } \\
\text { ochroną. }\end{array}$ & 11 & 10,00 \\
\hline $\begin{array}{l}\text { Nie powinno się szczepić w ogóle, ani } \\
\text { szczepionkami obowiązkowymi, ani dodatkowymi. }\end{array}$ & 1 & 0,91 \\
\hline Nie wiem/trudno powiedzieć & 11 & 10,00 \\
\hline Razem & 110 & 100,00 \\
\hline
\end{tabular}

Duży odsetek rodziców $(60,6 \%)$ uważał, że szczepienia są bezpieczne i tylko znikomy procent $(0,91 \%)$ jest przeciwny szczepieniu swoich dzieci z powodu mogących wystąpić powikłań.

Trudności rodziców w realizacji szczepień u dzieci wynikały najczęściej z wysokich kosztów szczepionek zalecanych $(56,4 \%)$ i braku rzetelnej wiedzy odnośnie szczepień $(28,2 \%)$.
Rodzice najczęściej byli też zmotywowani do szczepienia swoich dzieci wszystkimi szczepionkami obowiązkowymi i tylko niektórymi zalecanymi, bo były płatne $(30,0 \%)$, a $70,0 \%$ z nich deklarowało, że wybierze szczepionkę skojarzoną (tab.3).

Tab. 3. Deklaracja rodziców odnośnie wyboru rodzaju szczepień u swoich dzieci.

\begin{tabular}{|l|c|c|}
\hline \multicolumn{1}{|c|}{ RODZAJ SzCzEPIEŃ } & $\begin{array}{c}\text { Liczba } \\
\text { (n) }\end{array}$ & $\begin{array}{c}\text { Procent } \\
\text { (\%) }\end{array}$ \\
\hline tylko obowiązkowe, bo są bezpłatne & 20 & 18,18 \\
\hline tylko obowiązkowe, bo są wystarczające & 21 & 19,09 \\
\hline $\begin{array}{l}\text { wszystkie obowiązkowe i tylko niektóre zalecane, } \\
\text { bo są płatne }\end{array}$ & 33 & 30,00 \\
\hline $\begin{array}{l}\text { wszystkie obowiązkowe i tylko niektóre } \\
\text { najgroźniejsze zalecane, żeby nie było za dużo }\end{array}$ & 18 & 16,36 \\
\hline wszystkie obowiązkowe i wszystkie zalecane & 15 & 13,64 \\
\hline wybiórczo obowiązkowe na najgroźniejsze choroby & 2 & 1,82 \\
\hline tylko zalecane & 0 & 0,00 \\
\hline wybiórczo zalecane na najgroźniejsze choroby & 0 & 0,00 \\
\hline $\begin{array}{l}\text { żadne, bo w ogóle nie szczepię/nie będę szczepił/a } \\
\text { swojego dziecka }\end{array}$ & 1 & 0,91 \\
\hline Razem & 110 & 100,00 \\
\hline
\end{tabular}

\section{DYSKUSJA}

Szczepienia ochronne uznawane są za jeden z najbardziej skutecznych sposobów eliminacji chorób zakaźnych. Dane epidemiologiczne ujawniają, że choroby zakaźne wieku dziecięcego nadal stanowią poważny, lecz często niedostrzegany problem zdrowotny $[12,13,14,15]$. Prawdopodobnie wynika to $\mathrm{z}$ faktu, iż większość typowych chorób zakaźnych została częściowo lub całkowicie wyeliminowana, przez co nie stanowią już realnego zagrożenia. Wielu ciężkim chorobom i wynikającym z nich zagrożeniom można zapobiec, podając dziecku odpowiednio wcześnie szczepionkę.

$\mathrm{Z}$ drugiej strony podawanie szczepionek na masową skalę, a także stosowany niekiedy przymus wakcynacji budzą czasem opór wśród rodziców. W ostatnich latach nasilają się działania ruchów antyszczepionkowych, podważających sens nie tylko poszerzania programu szczepień, ale nawet realizacji programu obecnie obowiązującego. Pojawia się coraz więcej doniesień, opartych na słabych dowodach naukowych, dotyczących szkodliwego wpływu szczepień na zdrowie dziecka $[1,2,6,7,8,9,10,11]$. Wątpliwości autorów dotyczą: zbyt dużej liczby podawanych dzieciom szczepionek, zbyt wczesnego ich rozpoczynania i niebezpieczeństwa ich stosowania. Nie należy zapominać jednak o tym, że eliminacja wielu groźnych chorób zakaźnych nastąpiła właśnie dzięki szczepieniom ochronnym.

Rodzicom zalecane jest terminowe rozpoczynanie i realizacja immunoprofilaktyki u dzieci zgodnie $\mathrm{z}$ aktualnym programem szczepień ochronnych $[1,4,5,6,7,8,12,13,16,17]$. Wiedza rodziców niemowląt na temat znaczenia szczepień ochronnych jest niezwykle istotna w późniejszej prewencji chorób zakaźnych u dzieci. Przeprowadzone badania własne pokazały, 
że tylko niewielki odsetek rodziców posiada wystarczającą (wysoką) wiedzę na ten temat. Być może wynikało to $\mathrm{z}$ tego, że nikt z pracowników ochrony zdrowia im takich informacji nie udzielił. Podobne spostrzeżenia poczynili również inni autorzy (np. Tarczoń i wsp., Kuchar i wsp., Kochman i wsp.) $[1,2,3,6,11]$. Badania postaw rodziców wobec szczepień ochronnych w Polsce (np. Tymińskiej i wsp., Tarczoń i wsp., Kochman i wsp.) wykazały, że szczepienia jako narzędzie do walki z chorobami zakaźnymi, są przez nich akceptowane, co potwierdziły także badania własne $[1,6,11]$.

\section{WNIOSKI}

1. Postawy rodziców wobec szczepień ochronnych u dzieci w badanej grupie były zróżnicowane.

2. Wiedza rodziców na temat szczepień ochronnych jest niewystarczająca dla skutecznego realizowania immunoprofilaktyki u swoich dzieci i wymaga uzupełnienia.

3. Za najbardziej wiarygodne źródło i formę przekazu informacji o szczepieniach ochronnych u dzieci rodzice uznali indywidualne rozmowy z lekarzem i pielęgniarką, co należałoby odpowiednio wykorzystać.

\section{PIŚMIENNICTWO/REFERENCES}

1. Tymińska J, Wysocki J. Oszacowanie potrzeb edukacyjnych rodziców w zakresie szczepienia przeciwko pneumokokom na przykładzie wybranego gabinetu lekarza P0Z [Estimating educational needs of parents regarding pneumococcal vaccination on the example of a GP practice]. Nowa Pediatria. 2015; 19(3):102-108.

2. Majda-Stanisławska E, Sicińska J, Kuc A. Czy rezygnacja ze szczepień pneumokokowych jest bezpieczna? [Is it safe to opt out of pneumococcal vaccination?]. Forum Pediatrii Praktycznej. 2016; 10:51-56.

3. Kochman D, Rudzińska T. Znaczenie edukacji rodziców w kontekście szczepień [The importance of educating parents on vaccination]. Problemy Pielęgniarstwa. 2008;16:163-172.
4. Pirogowicz I, Kuchar E, Steciwko A. Szczepienia zalecane - optymalizacja postępowania wobec chorób infekcyjnych. [Recommended vaccinations - optimising the treatment of infectious diseases]. Family Medicine\&Primary Care Review. 2006; 8(3):1046-1052.

5. Pokorna-Kawałek D, Mastalerz-Migas A, Steciwko A. Szczepienia zalecane w praktyce lekarza rodzinnego [Vaccinations recommended in the practice of a GP] Terapia. 2010; 2:63-68.

6. Tarczoń I, Domaradzka E, Czajka H. Co na temat szczepień ochronnych wiedzą rodzice i pracownicy ochrony zdrowia [What parents and healthcare professionals know about immunization]. Przegląd Lekarski. 2009; 66:27-33.

7. Grzesiowski P. Szczepienia dla całej rodziny. Obowiązkowe szczepienia dla dzieci. [Immunization for the whole family. Compulsory immunization of children]. Lekarz. 2008; 9:98-107.

8. Wysocki J.: Postępy w dziedzinie szczepień ochronnych w 2008 roku [Developments in immunization in 2008]. Medycyna Praktyczna - Pediatria. 2009; 02:45-52.

9. Kuchar E, Szenborn L. Postawy antyszczepionkowe i możliwości polemiki [Antivaccination attitudes and possibilities for discussion]. Przewodnik Lekarza. 2010;05:43-46.

10. Szenborn L., Czajka H., Wysocki J. Kontrowersje wokół szczepień [Controversies over vaccinations]. Przegląd Lekarski. 2009; 1-2:65-70.

11. Kochman D, Rudzińska T. Analiza przyczyn decyzji rodziców o poddaniu szczepieniom dzieci w wieku 0-2 lat [Analysing the reasons behind parents' decision to have their children vaccinated at the age 0-2]. Pediatria Polska. 2008; 83:357-362.

12. Murkowicz J. Szczepienie przeciwko rotawirusom [Rotavirus vaccine] Medycyna Praktyczna. 2015;1 special issue: 3-23.

13. Majda-Stanisławska E. Choroby wywołane przez meningokoki w Polsce - charakterystyka i opis przypadków klinicznych [Meningococcal diseases in Poland - characteristics and description of clinical cases]. Pediatria Polska. 2009; 5:488-491.

14. Huppertz HI, Salman N, Giaquinto C. Risk factors for severe rotavirus gastroenteritis. Pediat Inf Dis J. 2008; 27(supl.):11-19.

15. Hjuler T, Wolhlfart J, Kaltoft MS. Risks of invasive pneumococcal disease in children with underlying chronic diseases. Pediatrics. 2008; 122:26-32.

16. Vesikari T, Karvonen A, Prymula R. Efficacy of human rotavirus vaccine against rotavirus gastroenteritis during the first 2 years of life in European infants: randomized, double-blind controlled study. Lancet. 2007; 370:1757-1763.

17. Vestrheim DF, Lovoll 0 , Aaberge IS. Effectiveness of a $2+1$ dose schedule pneumococcal conjugate vaccination programme on invasive pneumococcal disease among children in Norway. Vaccine. 2008; 26:3277-3281.

Praca przyjęta do druku/Manuscript received: 09.11.2016

Praca zaakceptowana do druku/Manuscript accepted: 13.12.2016

Tłumaczenie/Translation: Agnieszka Rybacka 